\title{
Indirect consequences of parental care: sex differences in ectoparasite burden and cleaner-seeking activity in longfin damselfish
}

\author{
Karen L. Cheney, Isabelle M. Côté* \\ Centre for Ecology, Evolution and Conservation, School of Biological Sciences, University of East Anglia, Norwich NR4 7TJ, UK
}

\begin{abstract}
Many direct costs of parental care have been described for teleost fishes, including reduced body weight, body fat and immune condition. However, few studies have focussed on the indirect consequences of reproduction. In this study, we investigated such consequences in the longfin damselfish Stegastes diencaeus (Jordan \& Rutter), a territorial reef fish in which the males provide parental care of eggs. More specifically, we examined patterns of spatial distribution of males and females in relation to substratum suitability for the establishment of nest sites and the consequences of spatial distribution for ectoparasite burden and cleaner-seeking activity. The territories of males and females differed significantly in a number of habitat features. Breeding males, with a nest site present in their territory, were found mainly at the periphery of reef patches, near sand, where vertical substratum suitable for nest sites is present, whereas females and non-breeding males were found in the centre of patches. Cleaning stations occupied by the cleaning gobies Elacatinus evelynae and E. prochilos were also located in peripheral areas, thus, in general, breeding males were closer to cleaning stations than females. Damselfish that were closer to cleaning stations visited them more frequently. During nest-guarding periods, males visited cleaning stations less frequently than during non-guarding periods, but this was not concomitant with an increase in ectoparasite loads during nest-guarding periods. Damselfish in peripheral territories had significantly lower ectoparasite numbers than those situated in the centre of reef patches. These results are consistent with a lower exposure of peripheral damselfish to ectoparasites. These intersexual differences in territory position, proximity to and use of cleaning stations, and ectoparasite loads are indirect consequences of sex differences in reproductive-resource requirements. Such interactions between breeding systems, distributional ecology and other aspects of non-reproductive behaviour are undoubtedly widespread, and their consideration could enhance our general understanding of reef-fish ecology.
\end{abstract}

KEY WORDS: Cleaning stations - Paternal care - Reef fish distribution - Stegastes diencaeus · Sex differences $\cdot$ Territoriality

\section{INTRODUCTION}

Many fish species exhibit parental care, with paternal care being the commonest form (Blumer 1982). Care can involve nest-building, egg oxygenation through fanning, guarding by chasing predators, and mouth-brooding (Smith \& Wootton 1995). The direct consequences of these activities have been documented in detail, and the costs of parental care can be high. Reduced body weight, body fat, and immune condition, as well as increased mortality (Okuda 2001), have all been shown in egg-caring males (Coleman \& Fischer 1991, Smith \& Wootton 1994, Balshine-Earn 1995, Guderley \& Guevara 1998, Okuda 2001). Parental care can also entail indirect consequences, which have been more rarely considered (Magurran \& Garcia 2000). In species exhibiting uniparental care, for example, sex-specific differences may arise from the need for one sex to provide suitable nest sites and protection from egg predators. If suitable nest sites 
were non-randomly dispersed through the habitat, sex-specific patterns of distribution could thus be generated which could have several repercussions on fish ecology and behaviour.

Intraspecific variation in distribution across habitats is a common feature among reef fishes (Nemtzov 1997). It has often been examined from the perspectives of ontogenetic shifts (Danilowicz 1997, Dahlgren \& Eggleston 2000) and intraspecific competition (Buchheim \& Hixon 1992), but has seldom been linked to gender. A notable exception is the study by Sikkel et al. (2000), who showed that yellowtail damselfish Microspathodon chrysurus found in shallow water close to shore tended to be females, while those in deeper water at the seaward edge of the fringing reef studied were more likely to be males. This sex-biased distribution across the reef was correlated with differences in ectoparasite burden and use of cleanerfish stations. More specifically, females had higher ectoparasite loads than males and also spent less time at cleaning stations, which were less abundant in shallower water (Sikkel et al. 2000). Unfortunately, it is not clear whether these differences in ectoparasite burden between the sexes were due to differences in cleaning station use, in exposure to ectoparasites in shallow versus deeper water, or to a combination of both factors. Nevertheless, this study suggested that sex-linked differences in distribution can have a variety of ecological and behavioural consequences.

In a previous study of habitat features important to relocating adult longfin damselfish Stegastes diencaeus (a common Caribbean species with male parental care), we noted sex-related differences in territory characteristics for a small sample of individuals (Cheney \& Côté 2003). Specifically, we found that the territories of males were closer to sand than those of females, which has potential implications for the overall distribution of males and females on reefs. Moreover, the quick colonisation, mainly by males, of artificially vacated territories with active nests suggested both that suitable nest sites have specific characteristics, and that territories with such sites are in limited supply (Cheney \& Côté 2003).

In the present study we expand our comparison of territorial characteristics of male and female longfin damselfish to investigate sex-biased spatial patterns of distribution, and link these explicitly to the sex-specific demands of parental care. We then examine the consequences of differences in small-scale pattern of distribution for cleaner-seeking activity and exposure to emerging ectoparasites, and ultimately for ectoparasite loads of male and female damselfish. Our study therefore highlights some unexpected non-reproductive consequences of paternal care for both sexes. Although we focussed on longfin damselfish, our results may be broadly applicable to the large number of coral reef fish species that are also characterised by territoriality and uniparental care.

\section{MATERIALS AND METHODS}

Study site and species. The study was conducted in July and August 2001 on the fringing reefs off the Bellairs Research Institute, in the Barbados Marine Reserve, Barbados, West Indies $\left(13^{\circ} 10^{\prime} \mathrm{N}, 59^{\circ} 30^{\prime} \mathrm{W}\right)$. The North and South Bellairs reefs are relatively degraded, with little coral cover (median 2 to $15 \%$ ), and are predominantly covered with filamentous turf algae that are grazed by abundant herbivores. The reefs are similar in structure and only separated by a narrow sand channel. There is considerable movement of fishes between the 2 reefs (Chapman \& Kramer 2000, K. L. Cheney pers. obs.).

The study sites consisted of 5 haphazardly chosen $10 \times 10 \mathrm{~m}$ areas located in the spur-and-groove zone of the South Bellairs reef ( 2 sites) and on truncated spurand-groove reefs of the North Bellairs reef (3 sites) at depths ranging from 3.5 to $6 \mathrm{~m}$. Patches of reef were separated by sand and typically had boulder-like substratum around their peripheries and dead coral and more rugose substratum in their centre. Sites were 26 to $42 \mathrm{~m}$ apart from each other and between 75 to $125 \mathrm{~m}$ from shore.

Longfin damselfish Stegastes diencaeus defend permanent mutually exclusive territories (ca. $1 \mathrm{~m}^{2}$ ) against a variety of intruders. Each territory provides its resident with food resources in the form of turf algal cover (Robertson 1984), and males may establish a nesting site within their territory by removing algae from a suitable vertical area of coralline rock, often creating a smooth red algae cover suitable for egg adhesion.

Spawning follows a lunar periodicity, with peak activity occurring at new moon. In our study population, longfin damselfish were reproductively active for 20 d each month (K. L. Cheney pers. obs.) (periods referred to as 'nest-guarding periods'), and showed no breeding activity during the remaining days ('nonguarding periods'). On spawning days, males entice gravid females into their territory to lay eggs, courting them with a succession of characteristic forays and circling the female with rapid movements. The males alone then guard egg clutches for $5 \mathrm{~d}$ until hatching. Males typically receive 3 to 5 egg clutches per month, and may care for several clutches of different ages at once. The length of the nest-guarding period therefore varies among individual males; moreover, not all males spawn during nest-guarding periods. We therefore refer to males with a nest site within their territory (either prepared or with eggs present) as 'breeding 
males', and those with no nest site and not seen engaging in any reproductive activity during the study as 'non-breeding males'.

Longfin damselfish are aggressive towards most common facultative cleaners such as juvenile bluehead wrasse Thalassoma bifasciatum, juvenile angelfish Pomacanthus spp. and Spanish hogfish Bodianus rufus; hence, cleaning gobies Elacatinus evelynae and E. prochilos represent their main fish cleaners. Both species were found at cleaning stations within the study areas. In this study we considered only coraldwelling gobies since gobies that live on sponges subsist mainly on polychaete worms embedded in sponge tissue (Whiteman \& Côté 2002). Cleaner shrimps (Periclimenes yucatanicus and $P$. pedersoni) were not observed in the study areas.

The territories of all 301 longfin damselfish in the 5 study areas were mapped by observing groups of fish for a minimum of 15 min to locate territorial boundaries. A large proportion (215 out of 301) of these longfin damselfish were sexed behaviourally during the study by observing spawning during the first hour of daylight, courtship throughout the day, or by location of nest sites during nest-guarding periods. Nearly half (41 out of 86) of the individuals that were not observed to partake in reproductive activity were caught in a hand-net and sexed by examining the shape of the urogenital papilla (23 females, 18 males; binomial test, $\mathrm{p}>0.25$ ). The remaining damselfish (45 individuals, or $15 \%$ of the total sample) that could not be sexed behaviourally could not be caught because of time constraints; these individuals were omitted from the analyses. We caught 53 randomly chosen males and 44 females by herding them individually into a barrier net and capturing them with a hand-net to measure their standard length to the nearest millimetre.

Territory characteristics. To assess variability in territory characteristics, we selected 164 individuals haphazardly (89 males, 75 females) and quantified the following territory parameters. The area of each territory was calculated by dividing the territory into triangles using coloured metal nuts and measuring each triangle side. The areas of each triangle were then calculated and summed to obtain the total planar area. Substratum cover was estimated using a $1 \mathrm{~m}^{2}$ quadrat with a $10 \times 10$ point grid, which was systematically moved to cover the entire territory. Under each point, substratum type (rock, rubble, sand, dead coral, live coral) and live cover type (coral, turf, sponge or macroalgae) were recorded. Substratum cover and live cover were then expressed as a proportion of total points in a territory. The planar distances of each territory from the nearest sand patch and the nearest cleaning station were measured. Territories within $1 \mathrm{~m}$ of sand were designated peripheral, whereas those more than $1 \mathrm{~m}$ from sand were designated as central territories. Rugosity was estimated using a substratum complexity index (SCI), i.e. the ratio of a $1 \mathrm{~m}$ length of chain as it follows the contours of the substratum compared to the straightline distance between the ends of the chain. An SCI of 1.0 indicates a flat surface, while higher SCIs indicate substrata of increasing complexity. The largest vertical drop along the chain was also measured to differentiate between a substratum with many small irregularities and a substratum with a flat surface and a single large vertical drop. A modified SCI was thus calculated as the length of the chain $(1 \mathrm{~m})$ minus the largest drop and compared to the standard SCI. A large difference between the 2 indices indicates a substratum with a large drop. For each territory we measured distance to the nearest cleaning station (m). For males, we also noted whether an active nest site was present within the territory.

Behavioural observations. We used focal-individual observations to quantify the level of use of cleaning stations by male and female damselfish, initially in relation to their territory location and breeding status (for males). Unfortunately, there were too few breeding males in central territories and too few nonbreeding males in general to allow a direct comparison. However, since we had previously shown that the main determinant of the rate of damselfish visits to cleaners is the travel distance between the damselfish territory and the cleaning station (Cheney \& Côté 2001), we compared cleaning station use of 15 breeding males and 15 female damselfish with cleaning stations in their territories with that of 10 breeding males and 8 females without cleaning stations in their territories. Despite the fact that all males observed were in peripheral territories and all females were in central territories, males and females without a cleaning station within their territorial boundaries did not differ in their distance to the nearest cleaning station (mean \pm $\mathrm{SD}$, males: $4.97 \pm 2.53 \mathrm{~m}$, females: $5.75 \pm 2.31 \mathrm{~m}$; Student's $t$-test $, t_{16}=0.68, \mathrm{p}=0.51$ ). These comparisons revealed the relative importance of distance to cleaning stations for cleaner use by males and females. This, combined with the known distances between peripheral or central territories and cleaning stations (see 'Territory characteristics' above), allowed us to infer the sex-specific role of territory location in use of cleaning stations.

Each focal damselfish was observed 8 times for 15 min periods, 4 times in the morning between 09:00 and $11: 30 \mathrm{~h}$, and 4 times in the afternoon between 13:30 and 16:00 h. This time span encompassed most of the period of daily cleaning activity, including the end of the morning peak in cleaning-bout duration and the beginning of the afternoon peak in client visit-rate 
measured on the Bellairs reefs (Côté \& Molloy 2003). More importantly, we have no evidence to date of differences between male and female damselfish in their diurnal pattern of use of cleaning stations (K. L. Cheney unpubl. data). We conducted 4 observations ( 2 in each time period) during nest-guarding periods and 4 during non-guarding periods. During each observation we recorded the amount of time damselfish spent at cleaning stations.

Ectoparasite emergence. Over a period of $6 \mathrm{~d}$, we placed 3 emergence traps on sand immediately adjacent $(<0.2 \mathrm{~m})$ to peripheral territories and 3 traps over a mixture of coral and rock in the centre of the study patch reefs. The traps consisted of nylon mesh $(200 \mu \mathrm{m})$ in a pyramidal shape with a $1 \mathrm{~m}^{2}$ base frame made of polyvinyl chloride (PVC) pipe filled with lead weights. A $750 \mathrm{ml}$ plastic bottle was placed at the cod-end, which extended $1 \mathrm{~m}$ above the trap. A small amount of air in the bottle provided positive buoyancy. Sampling bottles were changed and nets were cleaned to remove algae every $24 \mathrm{~h}$, when each trap was moved to a new location. There was therefore a total of 36 (24 h) samples. The number of gnathiid isopod larvae caught in each $24 \mathrm{~h}$ period was counted under a dissecting microscope. Larval gnathiids are the main reported prey item of most cleaner fishes (e.g. Labroides dimidiatus: Grutter 1996; Elacatinus prochilos: Arnal \& Côté 2000; Symphodus melanocercus: Arnal \& Morand 2001).

Ectoparasite-load assessment. At the end of the study, we collected 42 damselfish for ectoparasite-load assessment. Because of constraints in availability, we could not obtain samples for all combinations of gender, breeding status and territorial position during the nest-guarding and non-guarding periods. We therefore collected 16 breeding males ( 9 from peripheral territories, 7 from central territories), 12 females (6 each from peripheral and central territories), and 6 non-breeding males from central territories during the last nest-guarding period. During the last nonguarding period, we collected 8 breeding males from peripheral locations. All damselfish obtained from peripheral locations had a cleaning station within $1 \mathrm{~m}$ of their territorial boundary, which ensured frequent visits to cleaners (Cheney \& Côté 2001). In contrast, all damselfish from central territories were located more than $3 \mathrm{~m}$ away from the nearest cleaning station, a distance that effectively ensured no contact with cleaners (Cheney \& Côté 2001).

All damselfish were herded individually into a barrier net (4 mm mesh size) placed around the territory, captured with a hand-net and quickly placed into a hermetically sealed plastic bag. A small amount of clove oil (a natural anaesthetic) was sprayed into the bag causing the fish to die within $10 \mathrm{~s}$ with little evidence of pain or distress. The fish were then taken back to the laboratory where they were placed in a $0.4 \%$ chloretone bath (BDH Chemicals) for $1 \mathrm{~h}$ to remove ectoparasites (Grutter 1995). Each fish and its bag were then rinsed thoroughly with a wash bottle, and the entire surface of the fish, including gills and buccal cavity, was scraped gently with the nozzle of the bottle. We scanned 12 fish under a binocular microscope to ensure that all ectoparasites had been removed. All liquids were filtered, and ectoparasites were transferred from the filter paper into a Petri dish for identification under a binocular microscope.

Table 1. Characteristics of territories defended by breeding males, non-breeding males and female longfin damselfish Stegastes diencaeus. Distance from sand, Distance from cleaning station: planar distance of territory from nearest sand patch and nearest cleaning station, respectively; SCI: substratum complexity index (see 'Materials and methods' for details). ${ }^{*}$ Significant difference (Mann-Whitney $U$-test) between breeding males and non-breeding males + females after Bonferroni correction $\mathrm{p}<0.05$

\begin{tabular}{|c|c|c|c|c|c|c|c|c|}
\hline \multirow[t]{2}{*}{ Characteristics } & \multicolumn{2}{|c|}{ Breeding males $(\mathrm{n}=77)$} & \multicolumn{2}{|c|}{ Non-breeding males $(n=12)$} & \multicolumn{2}{|c|}{ Females $(\mathrm{n}=75)$} & \multicolumn{2}{|c|}{ Kruskal-Wallis tes } \\
\hline & Range & Mean $\pm \mathrm{SE}$ & Range & Mean \pm SE & Range & Mean $\pm \mathrm{SE}$ & $\chi^{2}$ & $\mathrm{p}$ \\
\hline Rock (\%) & $56.7-100$ & $80.1 \pm 1.1$ & $43.2-98.2$ & $82.1 \pm 1.2$ & $43.2-100$ & $77.6 \pm 1.5$ & 3.3 & 0.19 \\
\hline Rubble (\%) & $0-11.1$ & $1.6 \pm 0.3^{*}$ & $0-8.7$ & $1.2 \pm 0.3$ & $0-9.9$ & $0.6 \pm 0.2$ & 12.5 & $<0.001$ \\
\hline Sand (\%) & $0-27.2$ & $6.4 \pm 0.8^{*}$ & $0-24.3$ & $2.3 \pm 0.9$ & $0-18.5$ & $1.1 \pm 0.3$ & 41.6 & $<0.001$ \\
\hline Dead coral (\%) & $0-8.6$ & $0.1 \pm 0.6^{*}$ & $1.3-12.0$ & $8.2 \pm 2.1$ & $0-11.1$ & $9.1 \pm 2.2$ & 24.4 & $<0.001$ \\
\hline Live coral (\%) & $0-33.3$ & $12.7 \pm 0.9^{*}$ & $0-56.0$ & $18.2 \pm 1.4$ & $0-54.3$ & $17.6 \pm 1.3$ & 12.4 & $<0.001$ \\
\hline Turf (\%) & $46.9-100$ & $73.6 \pm 1.4$ & $45.2-98.0$ & $71.6 \pm 1.3$ & $43.2-100$ & $72.1 \pm 1.5$ & 3.0 & 0.23 \\
\hline Sponge (\%) & $0-4.8$ & $0.5 \pm 0.2$ & $0-3.4$ & $0.4 \pm 0.1$ & $0-5.0$ & $0.5 \pm 0.2$ & 0.5 & 0.77 \\
\hline Macroalgae (\%) & $0-24.7$ & $4.5 \pm 0.5$ & $0-17.5$ & $3.1 \pm 0.4$ & $0-18.5$ & $3.2 \pm 0.5$ & 5.1 & 0.08 \\
\hline Area $\left(m^{2}\right)$ & $0.4-2.6$ & $1.2 \pm 0.2$ & $0.4-1.0$ & $1.0 \pm 0.2$ & $0.3-1.7$ & $0.9 \pm 0.1$ & 0.1 & 0.92 \\
\hline Distance to sand (m) & $0-2.5$ & $0.2 \pm 0.1^{*}$ & $0-4.6$ & $1.5 \pm 0.3$ & $0-5.2$ & $1.6 \pm 0.1$ & 66.5 & $<0.001$ \\
\hline Standard SCI & $1.0-2.5$ & $1.3 \pm 1.8$ & $1.0-2.0$ & $1.5 \pm 1.2$ & $1.0-2.0$ & $1.4 \pm 1.4$ & 3.2 & 0.21 \\
\hline Modified SCI & $1.1-5.0$ & $2.6 \pm 0.2$ & $1.2-5.4$ & $1.8 \pm 0.1$ & $1.3-10.0$ & $1.7 \pm 0.3$ & 4.1 & 0.13 \\
\hline$\Delta \mathrm{SCI}$ & $0.1-3.0$ & $1.3 \pm 0.5^{*}$ & $0.2-3.4$ & $0.3 \pm 0.1$ & $0.3-7.5$ & $0.3 \pm 0.3$ & 63.2 & $<0.001$ \\
\hline $\begin{array}{l}\text { Distance from } \\
\text { cleaning station (m) }\end{array}$ & $0-6.3$ & $1.0 \pm 0.3^{*}$ & $0-5.6$ & $3.5 \pm 1.3$ & $0-4.2$ & $3.2 \pm 1.3$ & 52.1 & $<0.001$ \\
\hline
\end{tabular}


Statistical analysis. Territory parameters did not meet the assumptions of parametric testing. We therefore used Kruskal-Wallis tests to compare territory characteristics of breeding males, non-breeding males and females and, because of our large sample size, used the $z$ approximation to the Mann-Whitney $U$-test in pairwise comparisons. We also applied a sequential Bonferroni p-value correction to avoid the risk of Type I error resulting from multiple tests of nonindependent measures (Rice 1989). The interdependence of gender/breeding status, territory location and presence of a cleaning station within territorial boundaries was examined with a 3-dimensional contingency table. Partial independence of each factor on the other two was then tested following Zar (1999).

The time spent at cleaning stations by each focal damselfish was averaged across observations separately for nest-guarding periods and non-guarding periods. Cleaning-station use was then examined with a 3-way analysis of variance, with gender (males vs females), cleaning station (present in territory vs absent) and time period (nest-guarding vs nonguarding) as factors.

\section{RESULTS}

The sex ratio of longfin damselfish Stegastes diencaeus on our Barbadian study sites was significantly male-biased (151 males, 105 females; binomial test: $p<0.005)$. Male longfin damselfish were significantly larger than females (mean $\pm \mathrm{SD}$ length in $\mathrm{mm}=$ male $87.8 \pm 5.3, \mathrm{n}=53$; female $83.7 \pm 4.9, \mathrm{n}=44$; Student's $t$-test: $\left.t_{95}=3.93, \mathrm{p}<0.001\right)$.

\section{Territory distribution and characteristics}

Of the 151 males present at the study sites, 130 $(86 \%)$ were breeding males. Of these breeding males, $98 \%(128 / 130)$ were located in peripheral territories, compared with $14 \%(3 / 21)$ of non-breeding males and $31 \%(33 / 105)$ of females $\left(\chi^{2}=138.4, \mathrm{df}=2, \mathrm{p}<0.001\right)$. The relative numbers of non-breeding males and females in peripheral and central territories were not significantly different $\left(\chi^{2}=2.52, \mathrm{df}=1, \mathrm{p}=0.09\right)$. In contrast, breeding males were significantly more likely to occupy peripheral territories than non-breeding males and females $\left(\chi^{2}=135.6, \mathrm{df}=1, \mathrm{p}<0.001\right)$.

There were significant differences in territory characteristics among those breeding males, non-breeding males and female longfin damselfish whose territories were evaluated (Table 1). Pairwise comparisons revealed that there were no differences between the territory characteristics of non-breeding males and females (Mann-Whitney $U$-tests, $\mathrm{p}>0.05$ in all cases). However, the territory characteristics of breeding males were significantly different from those of nonbreeding males and females (Table 1). Non-breeding males and females were found on territories higher on the reefs, with significantly higher percentages of live and dead coral cover, while breeding males were located closer to the reef edges where the percentage cover of rubble and sand was greater (Table 1, Fig. 1). There was no difference in territory area or rugosity (measured with the standard SCI) between breeding males and non-breeding males and females (Table 1). However, the difference between standard and modified SCIs was significantly greater for breeding males (Table 1), indicating that breeding male territories had a single large vertical drop while the territories of nonbreeding males and females had more numerous small substratum irregularities.

A total of 58 cleaning stations were recorded across the 5 study sites; $84 \%$ ( 49 out of 58 ) of the cleaning stations were located at the periphery of patches, where

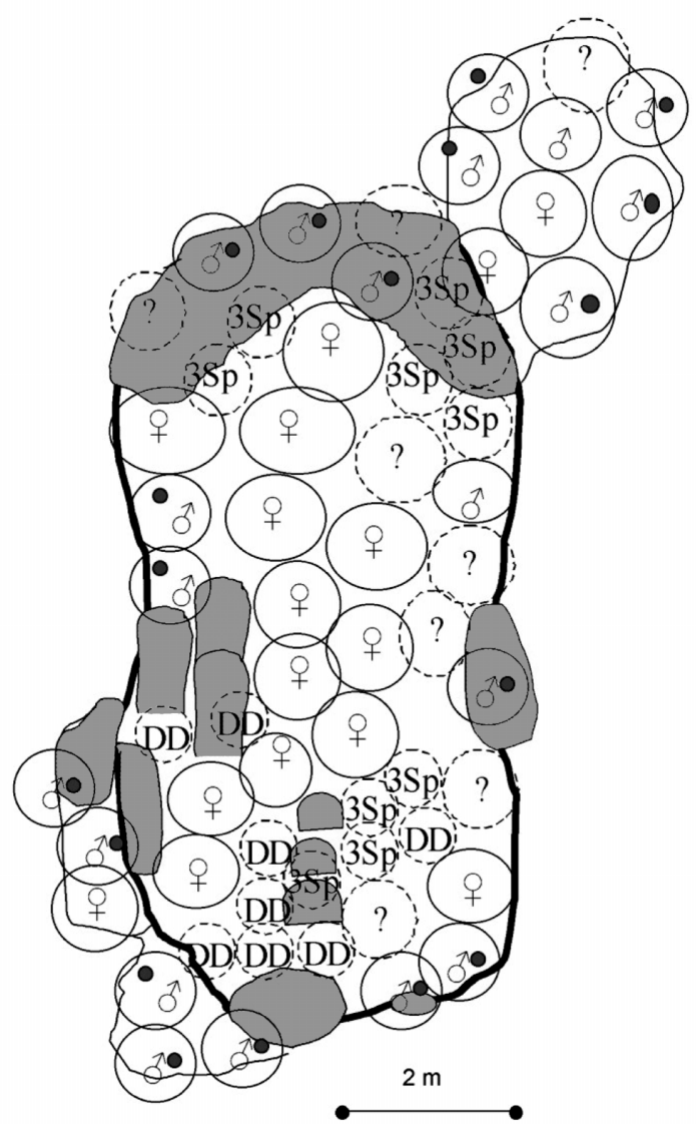

Fig. 1. Distribution of male and female Stegastes spp. territories on one of study patch reefs and presence of nest sites. ( $\square$ ) Coral heads $>30 \mathrm{~cm}$ diameter; (•) nest site; CS: cleaning station; DD: dusky damselfish $S$. dorsopunicans; 3Sp: 3-spot damselfish $S$. planifrons 
Table 2. Percentage of breeding male, non-breeding male and female Stegastes diencaeus occupying peripheral and central territories, with or without a cleaning station within their territorial boundaries (total $n=256$ individuals)

\begin{tabular}{|lcc|}
\hline Territory & \% with station & \% without station \\
\hline Breeding males & & \\
$\quad$ peripheral & 14.1 & 35.9 \\
$\quad$ central & 0 & 0.8 \\
Non-breeding males & & 1.2 \\
$\quad$ peripheral & 0 & 6.3 \\
$\quad$ central & 1.2 & 7.8 \\
Females & & \\
$\quad$ peripheral & 5.1 & 25.4 \\
$\quad$ central & 2.7 & \\
\hline
\end{tabular}

larger coral heads and overhangs occurred (Fig. 1). Only $23 \%$ (58/256) of longfin damselfish had a cleaning station within their territorial boundaries. Damselfish gender and breeding status, territory location and presence of a cleaning station within territorial boundaries were not mutually independent (Table 2) $\left(\chi^{2}=160.7\right.$, $\mathrm{df}=7, \mathrm{p}<0.001)$. Tests of partial independence revealed that each factor was significantly dependent on the other two (3-dimensional contingency tests, $\mathrm{p}<$ 0.001 in all cases); thus, breeding males were significantly more likely to have territories that were both peripherally located and with a cleaning station within them than either non-breeding males or females. As a result, breeding male damselfish were located significantly closer to cleaning stations, on average, than nonbreeding males or females (Table 1).

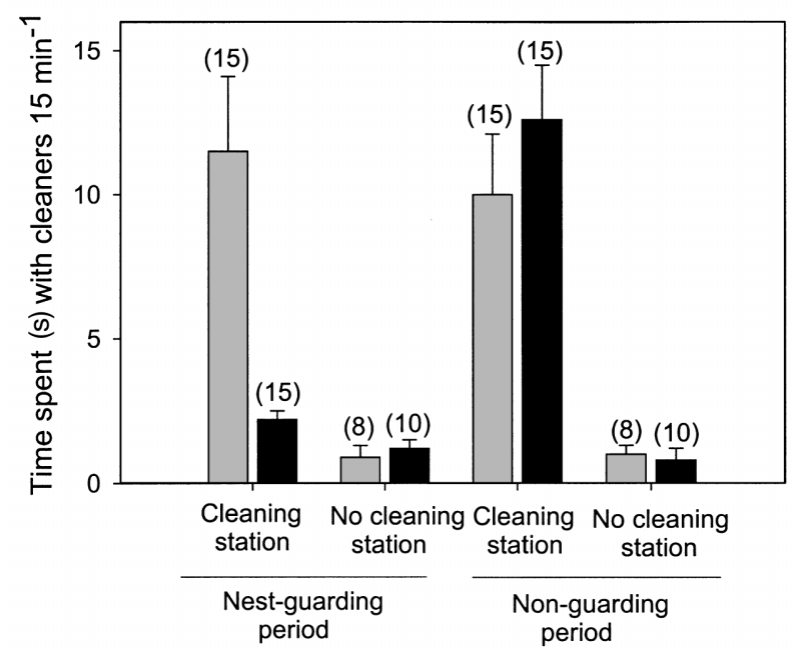

Fig. 2. Time spent (mean $+1 \mathrm{SE}$ ) at cleaning stations (s $15 \mathrm{~min}^{-1}$ ) by breeding male (black bars) and female (grey bars) Stegastes diencaeus in relation to presence or absence of cleaning stations within territorial boundaries during nest-guarding and non-guarding periods. Sample sizes in parentheses

\section{Use of cleaning stations}

In general, damselfish with cleaning stations in their territories spent a significantly longer time visiting cleaners than those without cleaning stations (Fig. 2) (3-way ANOVA, $F_{1,88}=147.9, \mathrm{p}<0.001$ ). There was a significant difference in time spent at cleaning stations between breeding males and females (3-way ANOVA, $F_{1,88}=4.70, \mathrm{p}=0.03$ ), as well as a significant difference in cleaning station use between nest-guarding and non-guarding periods ( 3 -way ANOVA, $F_{1,88}=4.83, \mathrm{p}=$ 0.03). Both differences stemmed from the reduced time spent with cleaners by breeding males with cleaning stations during nest-guarding periods (Fig. 2) (3-way ANOVA, sex $\times$ time period $\times$ cleaning station interaction, $F_{1,88}=12.96, \mathrm{p}=0.001$ ).

\section{Ectoparasite loads and emergence rates}

There were significant differences in ectoparasite loads among damselfish of different genders and territorial positions caught in nest-guarding and nonguarding periods (Fig. 3) (Kruskal-Wallis test, $\chi^{2}=$ 18.23, $\mathrm{df}=5, \mathrm{p}=0.003$ ). In particular, damselfish from peripheral territories with regular access to cleaning stations had significantly lower gnathiid numbers than damselfish from central territories with no access to cleaners (Fig. 3) (Mann-Whitney $U$-test, $z=4.13, \mathrm{n}_{1}=$

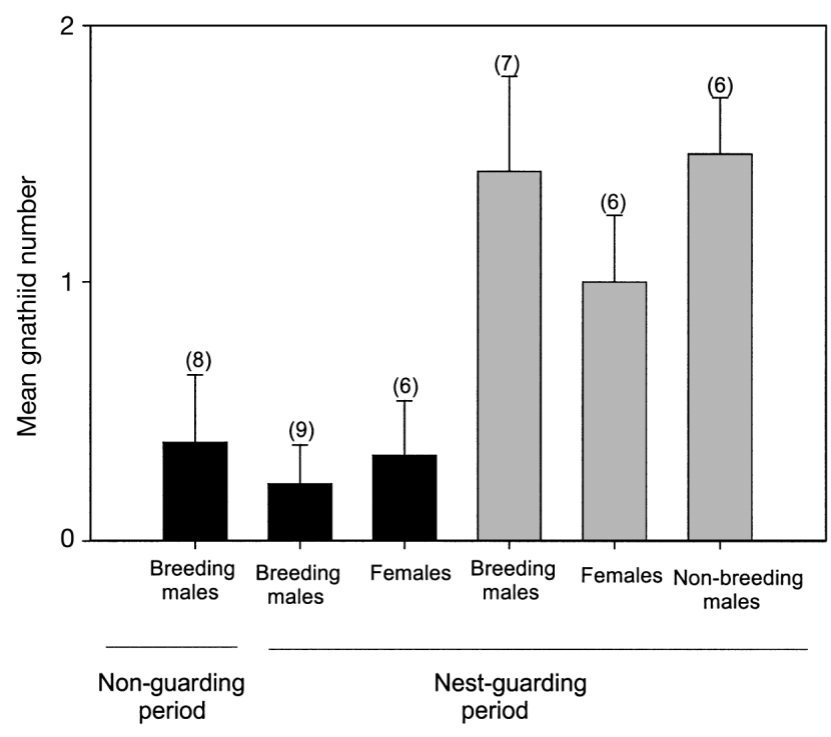

Fig. 3. Mean (+1 SE) number of gnathiid ectoparasites on breeding and non-breeding male and female Stegastes diencaeus during a nest-guarding period, and during a nonguarding period for breeding males. Sample sizes in parentheses. Black bars: damselfish in peripheral territories with access to cleaning stations; grey bars: damselfish in central territories without access to cleaning stations 
23, $\left.\mathrm{n}_{2}=19, \mathrm{p}<0.001\right)$. This difference held between breeding males in peripheral and central locations during nest-guarding periods (Fig. 3) (Mann-Whitney $U$-test, $z=2.65, \mathrm{n}_{1}=9, \mathrm{n}_{2}=7, \mathrm{p}=0.01$ ). Similarly, there was a tendency for females in peripheral territories to have lower gnathiid loads than those in central territories (Fig. 3) (Mann-Whitney $U$-test, $z=1.78, \mathrm{n}_{1}=6$, $\mathrm{n}_{2}=6, \mathrm{p}=0.08$ ). There was no difference in ectoparasite load among fish of different genders holding peripheral territories (Fig. 3) (Mann-Whitney $U$-test, $\chi^{2}=0.21, \mathrm{df}=2, \mathrm{p}=0.90$ ) or among those holding central territories (Fig. 3) (Mann-Whitney $U$-test, $\chi^{2}=1.69$, $\mathrm{df}=2, \mathrm{p}=0.43$ ).

Interestingly, there was no difference in gnathiid numbers between breeding males from peripheral territories caught during the nest-guarding period and during the non-guarding period (Fig. 3) (MannWhitney $U$-test, $z=0.26, \mathrm{n}_{1}=8, \mathrm{n}_{2}=9, \mathrm{p}=0.80$ ). There was also no relationship between damselfish size and gnathiid load, either separately for breeding males, non-breeding males, or females, or for all damselfish combined (Spearman rank-correlations, $p>0.05$ in all cases).

Emergence traps on sand, located adjacent to peripheral territories, yielded significantly fewer gnathiids than traps in the centre of the patch reefs (mean \pm SD: sand $0.06 \pm 0.24$ gnathiids $24 \mathrm{~h}^{-1}$, reef: $0.78 \pm 0.65$ gnathiids $24 \mathrm{~h}^{-1}$; Mann-Whitney U: $z=-3.75, \mathrm{n}_{1}=18$, $\left.\mathrm{n}_{2}=18, \mathrm{p}<0.001\right)$.

\section{DISCUSSION}

Caribbean longfin damselfish Stegastes diencaeus exhibited a distinct sex-specific distribution pattern on patch reefs. The majority of males were found in peripheral territories adjacent to sand, often characterised by large boulders with steep vertical drops appropriate for the establishment of nest sites. In contrast, non-breeding males and females were found mainly in the middle of patch reefs, in more finely rugose habitat. These sex differences in territorial position, which appear to be driven by the males' need for suitable nest-site substrata, had implications for proximity to cleaning stations and use of cleaners, exposure to ectoparasites and for ectoparasite loads.

Nest sites were non-randomly dispersed through the habitat because the periphery of reef patches supplied more vertical substratum, suitable for nest sites. On finely rugose habitat constructed of living or dead coral heads, nest sites were rarely found and territories were largely owned by non-breeding males and females. The importance of nests for males is reflected in their greater willingness to relocate as adults, particularly to territories with an established nest site (Cheney \& Côté
2003). Such territories, when they become available, are more aggressively fought for and are recolonized quickly (Itzkowitz et al. 1995, Cheney \& Côté 2003). In contrast, sexual success for females does not rely on finding and maintaining a nest site. Females are therefore less likely to relocate when they already own a feeding territory. In addition, females are also comparatively smaller than males and thus would be at a competitive disadvantage against males when a peripheral territory became vacant (Booth 1995, Webster \& Hixon 2000).

The non-random dispersion of nest sites coincides with the distribution of cleaning stations, which are most frequently located on large coral heads and overhangs on the peripheries of patches. The territories of breeding male longfin damselfish are therefore significantly closer, on average, to cleaning stations than those of non-breeding males or females. Although the presence of cleaning stations in vacant territories has no effect on the speed with which such territories are recolonised by male damselfish (Cheney \& Côté 2003), the visit rate of longfin damselfish to cleaning stations is distance-dependent, with fish living more than $2 \mathrm{~m}$ away from cleaners rarely using them (Cheney \& Côté 2001). Although both sexes in this study used cleaning stations equally during non-guarding periods, we confirmed that breeding males and females with cleaning stations within their territorial boundaries visited cleaners more often than damselfish living farther away from cleaning stations. Given that, due to their location on reef patches, a greater percentage of breeding males have cleaning stations in their territory than nonbreeding males or females, the breeding male population has increased access to cleaners. However, paternal care influences the ability or willingness of males to use cleaning stations. Despite their proximity to the stations, during nest-guarding periods, breeding males with a cleaning station in their territories reduced the time they spent with cleaners, and hence, reduced their travel costs. Damselfish territories with cleaning stations are intruded upon more frequently by non-territorial fish, including potential egg predators, than territories without cleaners (Arnal \& Côté 1998); therefore, guarding males may be forfeiting cleaning services to reduce the risk of predation on their brood. In contrast, females do not alter their cleaner-seeking activity during the reproductive cycle. Hobson (1971) also found that male garibaldi damselfish Hypsypops rubicunda guarding nests within their territory aggressively chased señorita wrasses Oxyjulis californica (the main cleanerfish off California), thus precluding cleaning interactions, whereas non-nest-guarding individuals were frequently cleaned. Therefore, patterns of use of 
cleanerfish tied to patterns of reproductive activity may be a common feature among fish species with parental care.

The non-random pattern of ectoparasite loads observed in this study, whereby peripherally located damselfish with access to cleaning stations had fewer ectoparasites than those in central territories without access to cleaners, is more consistent with the effect of differential exposure to parasites than with that of differential use of cleaning stations. If the frequency of use of cleaning stations determined ectoparasite load, then the shorter time spent with cleaners by breeding males during the nest-guarding period should have led to higher ectoparasite numbers on these males than during the non-guarding period. However, there was no difference in ectoparasite burdens of breeding males during nest-guarding and non-guarding periods, despite a 5- to 6 -fold difference in the time spent with cleaners. Interactions with cleaning gobies thus appear to have little effect on damselfish ectoparasite loads, although Cheney \& Côté (2001) found a small but significant increase in gnathiid number on damselfish that never used cleaning stations compared to those with regular access to cleaners, given comparable territorial positions. In contrast, damselfish in peripheral territories may be exposed to fewer emerging ectoparasites. Peripheral territories had edges bordering extensively on sand, a habitat from which significantly fewer gnathiid larvae emerged than from coral and coralline rock (see also Jacoby \& Greenwood 1988). Although the details of gnathiid infestation (such as the time spent in the water column by their larvae and the distance travelled before a host is colonised) are not yet known, recent evidence suggests that colonisation may occur relatively quickly after emergence (Sikkel et al. in press). Finally, the lower parasite loads of peripheral damselfish could also be explained if these individuals are in better condition and therefore less susceptible to ectoparasite infestation. However, there was no size difference between either females or breeding males in peripheral and central territories (Student's $t$-tests, $p>0.86$ in both cases), and body size is a good predictor of breeding status, at least in male longfin damselfish (Cheney \& Côté 2003). Although breeding males and females had similar ectoparasite loads when occupying similar territorial locations, the fact that relatively more breeding males are found in peripheral territories suggests that they should, on average, harbour fewer gnathiids than non-breeding males or females.

Intraspecific differences between sexes occur due to inequalities between maternal and paternal requirements, and here we have shown that the breeding system of a species, and its resulting sex-specific requirements in resources, can differentially influence the spatial distribution of males and females, which in turn affects other aspects of behaviour and ecology. In the case of longfin damselfish, male parental care has the indirect consequences of restricting most males to peripheral territories and preventing them from using cleanerfish for extended periods each month, despite their proximity to cleaning stations. However, this potential cost appears to be outweighed by the lower exposure to ectoparasites that males experience as a result of their peripheral territorial positions. Such interactions between breeding systems, distributional ecology and other aspects of non-reproductive behaviour are undoubtedly widespread, and their consideration could enhance our general understanding of reeffish ecology.

Acknowledgements. We thank everyone at the Bellairs Research Institute for logistical support, especially the director, Dr. B. Downey. K.L.C. was sponsored by a PhD studentship awarded by the Biotechnology and Biological Sciences Research Council of the UK, and we are grateful to the John and Pamela Salter Charitable Trust and the University of East Anglia for financial support. This manuscript was much improved by the comments of 3 anonymous reviewers.

\section{LITERATURE CITED}

Arnal C, Côté IM (1998) Interactions between cleaning gobies and territorial damselfish on coral reefs. Anim Behav 55: 1429-1442

Arnal C, Côté IM (2000) Diet of broadstripe cleaning gobies on a Barbadian reef. J Fish Biol 57:1075-1082

Arnal C, Morand S (2001) Importance of ectoparasites and mucus in cleaning interactions in the Mediterranean cleaner wrasse Symphodus melanocercus. Mar Biol 138: $777-784$

Balshine-Earn S (1995) The costs of parental care in Galilee St Peter's fish, Sarotherodon galilaeus. Anim Behav 50:1-7

Blumer LS (1982) A bibliography and categorization of bony fishes exhibiting parental care. Zool J Linn Soc 75:1-22

Booth DJ (1995) Juvenile groups in a coral-reef damselfish density dependent effects on individual fitness and population demography. Ecology 76:91-106

Buchheim JR, Hixon MA (1992) Competition for shelter holes in the coral-reef fish Acanthemblemaria spinosa Metzelaar. J Exp Mar Biol Ecol 164:45-54

Chapman MR, Kramer DL (2000) Movement of post-settlement fishes within and among fringing coral reefs in Barbados. Environ Biol Fish 57:11-24

Cheney KL, Côté IM (2001) Are Caribbean cleaning symbioses mutualistic? Costs and benefits of visiting cleaning stations to longfin damselfish. Anim Behav 62:927-933

Cheney KL, Côté IM (2003) Habitat choice in adult longfin damselfish: territory characteristics and relocation times. J Exp Mar Biol Ecol 4041:1-12

Coleman RM, Fischer RU (1991) Brood size, male fanning effort and the energetics of a nonshareable parental investment in bluegill sunfish, Lepomis macrochirus (Teleosti, Centrarchidae). Ethology 87:177-188

Côté IM, Molloy PP (2003) Temporal variation in cleanerfish and client behaviour: does it reflect ectoparasite availability? Ethology 109:487-499 
Dahlgren CP, Eggleston DB (2000) Ecological processes underlying ontogenetic habitat shifts in a coral reef fish. Ecology 81:2227-2240

Danilowicz BS (1997) The effects of age and size on habitat selection during settlement of a damselfish. Environ Biol Fish 50:257-265

Grutter AS (1995) Comparison of methods for sampling ectoparasites from coral reef fishes. Mar Freshw Res 46: 897-903

Grutter AS (1996) Parasite removal rates by the cleaner wrasse Labroides dimidiatus. Mar Ecol Prog Ser 130: 61-70

Guderley H, Guevara RC (1998) Physiological correlates of paternal care in male threespine stickleback. Ecoscience 5:438-447

Hobson ES (1971) Cleaning symbiosis among California inshore fishes. Fish Bull US Fish Wildl Serv 69(3):491-523

Itzkowitz M, Itzkowitz DE, Shelly D (1995) Territory use and disuse in the beaugregory damselfish. Bull Mar Sci 57: 653-662

Jacoby CA, Greenwood JG (1988) Spatial, temporal, and behavioural patterns in emergence of zooplankton in the lagoon of Heron Bay, Great Barrier Reef, Australia. Mar Biol 97:309-328

Magurran AE, Garcia M (2000) Sex differences in behaviour as an indirect consequence of mating system. J Fish Biol $57: 839-857$

Nemtzov SC (1997) Intraspecific variation in home range exclusivity by female green razorfish, Xyrichtys splendens

Editorial responsibility: Simon Archer (Contributing Editor), Guildford, UK (family Labridae), in different habitats. Environ Biol Fish 50:371-381

Okuda N (2001) The costs of reproduction to males and females of a paternal mouthbrooding cardinalfish Apogon notatus. J Fish Biol 58:776-787

Rice WR (1989) Analyzing tables of statistical tests. Evolution 43:223-225

Robertson DR (1984) Cohabitation of competing territorial damselfishes on a Caribbean coral reef. Ecology 65: 1121-1135

Sikkel PC, Fuller CA, Hunte W (2000) Habitat/sex differences in time at cleaning stations and ectoparasite loads in a Caribbean reef fish. Mar Ecol Prog Ser 193:191-199

Sikkel PC, Cheney KL, Côté IM (2003) In situ evidence for ectoparasites as a proximate cause for cleaning interactions in coral reef fish. Anim Behav (in press)

Smith C, Wootton RJ (1994) The cost of parental care in Haplochromis argens (Cichlidae). Environ Biol Fish 40: 99-104

Smith C, Wootton RJ (1995) The costs of parental care in teleost fishes. Rev Fish Biol Fish 5:7-22

Webster MS, Hixon MA (2000) Mechanisms and individual consequences of intraspecific competition in coral-reef fish. Mar Ecol Prog Ser 196:187-194

Whiteman EA, Côté IM (2002) Cleaning activity of two Caribbean cleaning gobies: intra- and inter-specific comparisons. J Fish Biol 60:1443-1458

Zar JH (1999) Biostatistical analysis, 4th edn. Prentice-Hall, Upper Saddle River, NJ

Submitted: December 16, 2002; Accepted: April 29, 2003

Proofs received from author(s): October 1, 2003 